\title{
A Sample of the Syrian Refugee Students' Degree of Psychological Alienation in Jordan
}

\author{
Dr. Nizar A. Shammout \\ Department of Educational Psychology, Faculty of Education Sciences \\ Hashemite University, Zarqa, Jordan
}

Doi:10.5901/jesr.2016.v6n3p135

\begin{abstract}
This study aimed at identifying the degree of alienation of the students of the Syrian refugee residing in both the refugee camps and cities, and to find out whether there were differences among the study sample's degree of alienation attributed to the variables: achievement, gender, number of alienation years, and the place of residence. To achieve this aim, the researcher applied a 70-item questionnaire divided into seven domains : loss of feeling, normlessness, powerlessness, nonfeeling of value, loss of aim, meaningless, self-centrality. The study sample consisted of (378) male and female students, who were selected from the ninth and tenth graders of the schools dedicated to the refugees, inside Mraijeeb Camp, Al-Mkhaizen Camp and Zarqa city. The results of the study indicated that the degree of alienation of the Syrian students was medium on the first, second and seventh dimensions. On the other hand, it was low on the third, fourth, fifth and sixth dimensions. Also, the study showed statistically significant differences in the degree of alienation of the Syrian refugee students attributed to gender on the first, second, third, fourth, sixth and seventh dimensions, statistically significant differences attributed to the number of alienation years on the third, fourth, and fifth dimensions, statistically significant differences attributed to study achievement on the seven dimensions of the scale, and finally statistically significant differences attributed to the place of residence variable (camp, city) on the first, second, fourth, sixth and seventh dimensions.
\end{abstract}

Keywords: Psychological alienation, refugee students.

\section{Introduction}

The decline of the economic situations and internal struggles in many countries of the world, led to the displacement of many people from their homelands, in great numbers, either in search of livelihood or to escape the raging conflicts in their own countries. As a result, alienation grew to become a multidimensional humanistic phenomenon. Being displaced from the homeland is one of the most influential types of alienation, on the individual's psychological adaptation and security, which will negatively reflect on all his/her life aspects. The reason is that he/she does not know what will come next, and suffers of both psychological and social instability. This makes the individual unable to invest his energies, abilities and capabilities. Subsequently, he cannot actualize himself. As an example, Syria is one of the most bloody and dispute countries due to the civil war taking place until this date. This situation led to the displacement of many citizens outside their homelands. Jordan is the most receiving country of the Syrian refugees, whose number exceeded one million. They were hosted into camps, and some were distributed over cities. These refugees are suffering from psychological, social, economic and adaptive conditions, because of their displacement, escaping the hardship prevailing in their country. Naturally, they began suffering from feeling of strangeness due to these conditions.

The psychologists and sociologists assured that this phenomenon has its negative reflections on the individual, once he is displaced from his homeland. In this concern, the alienation is considered a socio-psychiatric phenomenon, which captured the attention of many thinkers and literati, and care in it began as a psychological phenomenon. Studies in the psychological alienation field concluded that there is a number of psychological characteristics of the expatriate.

Gross et al (2001) assured that depression is one of the reasons for health problems the immigrants suffer, and is related to the social isolation. Alienation is among the basic, social activities through the family, race, or the caste, which becomes a basic component of the culture methods, (Zahran, 2004).

Alienation problem is the clearest problem, which most important features is the displacement of the person from his self and community, which, in turn will lead to psychological disorders (Daugherty \&Lentor, 2003).

Alienation leads to the loss of feeling of belonging, non-adherence to the criteria, inability, failure to feel the value, loss of the objective, centering around the self, low motive, loss and anxiety, fear of the future, and feeling of separation from others and self or both. (Paik \&Michichael, 2000).

Marc and Cary (2003) emphasized that what causes the alienation feeling is that the persons goes far from the 
basic thing he wants to be. In other words, goes very far beyond his basic motives. (Marc \& Cary, 2003).

In this case, we shall see him doing only little things he wants to do, and too many of the things he does not want to do, still he is unable to do them, in fact.

Bronfen (1986) notes that the expatriate is the one who has poor feeling of belonging, a sense of break-off, lack of interaction with the family, friends, or workplaces. Alfred, P. Rovail\& Mervyn, J. Wightina, 2005).

Hegel (1977) indicated that the expatriate, in the historical sense of word, is the one who lives in dead, nonhumanitarian world (Hegel, G. W. 1977).

Horney (2001), relates the alienation reasons with the individual to internal pressures, as the individual directs his activity toward achieving the highest possible ranks in order to realize the ideal image he aspires (Mousa, 2002, p.19).

Milgram (1998) noted that the feelings of separation from others and alienation paralyzes, in general, the sense of responsibility, and decreases the enjoyment of the public contribution and activities. (Zahran, 2004).

Goffman (1972) assures that the individual looks in quarrel or dispute with certain complicated situations in the daily or life systems, regarding the activities and meanings. (Semmer, N. K., 2002).

Kobasa (1979) finds that the expatriate feels that undertaking and adherence to the high purposes, ends or objectives, even though they are a part of the universe, are an affair that is much higher than his selfness and abilities (Kobasa, S. O., 1979).

Mau (1992) emphasizes that the sense of strangeness is mainly stemming from the lack of social support to the individual, and the lack of social interaction as well. (May, R. Y. 1992).

Homey (2001) ascribes the reasons of alienation with the individual to internal pressures, as the individual directs most of his activities to approach the highest perfection degrees, in order to realize his ideal self, and reach the image he drew to himself. (Mousa, 2002, p.19).

Marc \& Cary (2003) noted that many of the theorists in the social psychology, such as Goffman (1972); Kanugoo (1982); and Maslach (2001), see that alienation is the antonym and opposite of correlation, avowal, adherence and contracting. (Marc \& Cary, 2003).

Adler explained that the successful accordance requires reality that enables the individual deal positively with the life problems. On the other hand, mismatching occurs because of the avoidance of confronting and interaction with the various life problems. (Leak, G. K. Williams, D. E. 1989).

Blenner sees that Alienation is a reflection of cracks and landslides in the organic relationship between man and his existentialexperience. It concerns what happens to the man of psychological and mental disorders, and what he feels of alienation from the world and listlessness in his relations with others. (Iskander, 1988).

Fromm defined alienation psychologically as the failure in interaction between the psychological and social factors. The expatriate, as seen by Fromm looks at the world and himself as a commodity, which could be sold and bought, having only financial value. (Daminhouri, 1996).

Yahya (1997) indicates that expatriation, as a concept, widened to comprise different cases of psychology, such as: loneliness, straying, meaninglessness, non-normative, rebellion, separation, and lack of relatedness between two cases or conditions, such as work, and self-esteem. As a result, alienation is generally employed as psychological and social interpretation of the wide range of the human behavior. (Yahya, 1997).

The psychological alienation is procedurally definedas the student's sufferings of the features of loss of belongingfeeling, non-adherence to the criteria, inability, lack of value feeling, loss of target, loss of meaning, and centralizing around the self, through the total degree he achieves on the alienation scale employed in this study.

The researcher sees that the feeling of expatriation is the self-alienation, and subsequently, alienation from others. It also leads to ignore the abilities, capabilities, and relations, which the expatriate previously used to enjoy. In addition, he feels isolation, loss of identity, and absence of the community objectives and standards.

Built on the above, the study of alienation, identifying it and how it is measured and defined, and identifying its psychological effects and relatedness to other variables, lead us to help people who suffer from the feeling of alienation, in order to reach with them the psychological stability, and adaptation with the surrounding where individual lives, confidently and happily.

\section{Review of Literature}

Al-Mahmadawi (2007) conducted a study, which aimed to explore the extent of the existence of a statistically significant relation between the alienation and psychological adjustment of the Iraqis in Sweden. The study also aimed to find out whether or not are there statistically significant differences in alienation, based on the following variables: 
(Gender, age, marital status, number of alienation years, level of academic achievement). This study was conducted on a sample of Iraqis residing in Sweden, and it comprised (300) individuals of different areas in Sweden and governorates which are hosting the Iraqis more intensively. The researcher applied the alienation scale, which was made by him, and the results showed a negative, statistically significant relationship between alienation and psychological adjustment. On the other hand, the study found statistically significant differences between the psychological alienation and psychological security.

TaehanKanhoHakoeng (2004) made a study aimed to identify the factors affecting the alienation feelings with the high school graders. The study consisted of (550) male students of the academic secondary and vocational schools. The results indicated that the children of the medium class are the least in terms of alienation. Meanwhile, the alienation feeling was higher with the lower class children. The alienation feeling showed a negative relation to a wide extent with tens of the responses; such as: parenthood style, family consistency, school facilities, academic performance, relations with the peers, self-control, and social skills. Alienation indicator was stronger among the secondary school students, school facilities, self-control, relations with the peers, family consistency, parenthood style, and calculation of the academic performance, stronger than variance in alienation among the secondary school graders. This study showed a number of factors affecting alienation, such as school facility, self-control, relations with the peers, family consistency, parenthood style and academic performance.

Bushra (2006) conducted a study aimed at identifying the prevalence extent of the psychological alienation and its relation with the following demographic variables: sex, academic level (degree), family status, country where the student studies, and language of study. The study further aimed to reveal the main problems facing these students, and their relations with the abovementioned variables; and to identify the nature of the correlational relation between feeling the psychological alienation and these problems. To this end, the researcher constructed the psychological alienation scale, and the study sample comprised 190 male and female students of the different educational stages (BA, MA, Ph.D.) who are studying in the universities of Egypt, Russia and France. The study results showed statistically significant differences in the alienation feeling among the students according to academic level variable. The differences were in favor of the doctorial students, who were the least in terms of alienation. There were no statistically significant differences in the alienation feeling degrees based on the gender variable.On the other hand, there was a positive correlational relation between the alienation feeling degree based on the gender variable; and a positive correlational relation between the alienation feeling degree and the problems the study faces.

Mousa (2002) conducted a study aimed at identifying the existence of the alienation phenomenon with the students of Damascus (Syria) University, and its relations with certain demographic variables, such as age, gender, university year, and majoring. It also aimed to identify the relationship of the alienation feeling with the extent of achieving the students' psychological needs, based on the abovementioned variables. The study sample comprised (568) male and female students of many faculties (medicine, civil engineering, literatures, journalism). The researcher developed the psychological alienation scale and the psychological needs scale. The study results showed that there were no statistically significant differences in the alienation feeling attributed to the gender and academic year variables; while there were statistically significant differences in the alienation feeling ascribed to the age and specialization (major) variables. In this concern, the study showed that the older students and the students of the scientific faculties were the less tending to alienation than the younger students and the theoretical colleges students. The study further showed that there were no statistically significant differences concerning realizing the psychological needs with the university students with the university students, which are attributed to gender, age or academic year, or majoring variables. However, there was a correlational relation between alienation feeling level and actualizing level of the psychological needs with the university students, which are ascribed to gender, age, academic year or majoring variables.

Sugiure (2000) conducted a study to identify the relation between two types of motives in belonging, namely: sensitivity and rejection in terms of the belonging and alienation matter, as per the gender variable. The study sample amounted (127) male and female students of the Japanese secondary schools and universities. The study instrument was questions concerning the motive, belonging, alienation, and self-identity. The results showed that there was a large number of the students (sample members) who feel poor belonging, and still a large number feeling lack of belonging. The tendencies of belonging were negative in their relatedness to alienation; i.e. the more the alienation feelings are, the less the belonging feeling is. On the other hand, tendency to rejection was positive in its relation with alienation; the rejection of alienation was negative with the female students of the $1^{\text {st }}$ secondary class, but was positive with the male students in the universities (Sugiure, 2000).

Mohammad (2000) made a study aimed to identify the alienation prevalence degree, and its relations with certain personality traits; and aimed to know the effect of the sex variable on alienation. The study sample consisted of (164) 
male and female students of the United Arab Emirates University, (58 males and 106 females). The researcher employed the alienation scales, which he personally developed and prepared, with (50) items distributed over five dimensions: (inability, meaninglessness, non-normative, social isolation and self-alienation). He further used another scale about the personality traits, which was also developed by the researcher. The study results showed statistically significant differences between the male students and the degrees of the female students in the alienation dimensions.

Al-Naeemi (2005) conducted a study to disclose the psychological alienation and its relation with the need for selfbelonging; the social alienation and its relation with the need to belong to the community; and the cultural alienation and its relation with the need for knowledge. The study sample comprised (450) students in the difference educational stages (elementary, secondary and university). The researcher employed the alienation scale, which consisted of (38) items, and another scale for needs, which consisted of (37) items. The results showed that the faculties of all the stage are suffering from alienation conditions; and that the females are more alienated than the males with statistical significance. The results also showed that there were no statistically significant differences between the males and females in their need to belong to the community. Meanwhile, the results showed that the females are more needful to knowledge than males, with statistical significance. Finally, the study showed that there were no statistically significant differences in the three needs attributed to the gender and achievement variables (Al-Naeemi (2005).

Mahoney and Quick (2001) conducted a study that aimed to reveal the existence of the alienation feelings with the university students in the United States of America, in addition to reveal the relation between alienation and the gender variable; and the roles which the university may provide promote the status of the United States. The researcher employed Gould's Alienation Scale, which consisted of (44) statement and questions. The results showed that there are no statistically significant differences in the feeling level of alienation according to the gender variable. The study assured that the university atmosphere helps in alleviating the degree of alienation feeling; and that the students who have high degree of alienation may cope with this phenomenon. Finally, the study found that the students who obtained high degrees in alienation may be more tolerant toward the delinquent behavior in terms of the established social scale (Mahoney and Qucik, 2001).

Safopour et al (2010) conducted a study aimed to investigate the alienation feeling of the students of the secondary schools, as well as the effect of gender and type of the first grade immigration. In other words, those who themselves experienced the immigration from the country they were born to another country. The second category is those who were subject to $2^{\text {nd }}$ grade displacement, meaning those who were originally born in another country. The third category was the native citizens who were not subject to any displacement by themselves as well as their fathers. The study sample consisted of 446 students whose ages ranged between 15 and 19 years, and who responded to the alienation scale questions, prepared by (Joser and Joser).

The results showed that the adolescents of the first category had higher degrees on the dimension concerning the feeling of social isolation. Meanwhile, the second category showed higher degrees on the dimension concerning the loss of meaning, as compared to the second and third categories. As for the age variable, the results showed a statistically significant relation of the social alienation, which was high with the younger students. On the other hand, the degrees of the students who achieved 17 years old had lower degrees.

The study of Al-Aqeel (2014), aimed at identifying the psychological alienation phenomenon with a sample of the Syrian refugees in Jordan. The researcher employed the descriptive, survey method. To achieve the study objectives, a questionnaire comprising (96) items was constructed, which was distributed over eight basic domains: nonstandardization, meaninglessness, social isolation, insurgency, objectification, lack of objective, inability and selfalienation. The study was applied on a sample consisting of (251) refugees, who were selected the way available, according to the age, sex, social condition, and academic level variables. The results showed that there was a medium psychological alienation degree with the Syrian refugees. The results also showed that there was a statistically significant indicator that the meaninglessness with the females was higher than that of the males; and that the level of the psychological alienation within the domains of the social isolation, insurgency, lack of the target, inability, and selfalienation were higher with people 40 years and more old, as compared with the age groups that are less than 40 years. In addition, the study showed that the lack of standard level, social isolation, inability, and meaninglessness were higher with those whose academic level is less than the secondary stage, as compared with the Diploma Certificate holders; and that there is a higher level on the same dimensions with those holding higher studies, as compared with the holders of the BA and less.Finally the results showed that the alienation level with its dimensions (insurgency, lack of target, inability, meaninglessness, self-alienation, and the total degree) were higher with the married than the unmarried; that alienation is higher with the married than that of the divorced; and alienation with the widowed was higher as compared with that of the single and divorced individuals. 


\section{Statement of the Problem}

It is well established that immigration and coercive displacement of the individual outside his/her homeland lead him/her to feel alienation from the motherland. This, in turn, leads to the occurrence of many adaptive, psychological, and social problems. Most often, students are most affected as they feel alienation and are affected more by it than others, because they are farer from their domicile, schools and schoolmates, which makes them less adaptivewith the new school environments and less belonging to them, which, in turn, will negatively reflect on their achievement. Studies on this issue assured that there are many demographic changes, that are influencing and are influenced with the alienation feeling degree, such as sex, type and place of residence, and number of alienation years. This study had been made to explore the alienation feeling degree with the Syrian students, who are studying in the camp schools, and those in the public schools, which live inside the cities. The study also aimed to find out the effect of certain demographic variables (achievement, gender, place of residence (camp, city), and years of expatriation; and to examine the reality of alienation with these students.

The study problem is limited to the answers of the following questions:

1) What is the degree of alienation of the Syrian refugee students?

2) Are there statistically significant differences at $(\alpha=0.05)$ level in the alienation degree with the Syrian refugee students, ascribed to gender (male, female)?

3) Are there statistically significant differences at $(\alpha=0.05)$ level in the alienation degree of the Syrian refugee students, ascribed to the years of alienation?

4) Are there statistically significant differences at $(\alpha=0.05)$ level in the alienation degree of the Syrian refugee students, ascribed to academic achievement?

5) Are there statistically significant differences at $(\alpha=0.05)$ level in the alienation degree with the Syrian refugee students, ascribed to the place of domicile?

\section{Significance of Study}

The importance of the study lies in that it will shed lights on the reality of alienation feeling with the Syrian refugee students, and its reflection on their achievement. The results of this study will contribute in bringing the responsible people into the factuality of the psychological problems, which are related to alienation of these students, and work toward alleviating the effects of such problems. The study will assist the educational and psychological counselors to know that actuality of the problems connected with the refugee students' feeling of alienation, and work toward setting preventive, developmental and remedial programs for these students.

\section{Method and Procedures}

\subsection{Study Population}

The study population consisted of all the ninth and tenth graders in the schools (4 sections) of Mraijeeb Al-Fohood and Al-Mkhaizen Camps (Al-Azraq Area) for the Syrian refugees; as well as the students studying the public schools in the City of Zarqa, for the same classes, in the schools allocated for the Syrian refugees inside the City of Zarqa (4 sections).

\subsection{Study Sample}

The questionnaire was applied on the available sample comprising all themale and female ninth and tenth graders in the schools of Mraijeeb Al-Fohood and Al-Mkhaizen Camps (Al-Azraq Area); as well as all the ninth and tenth graders in the schools allocated for the Syrian students in the City of Zarqa, which belong to the Jordanian Ministry of Education. The total sample was (378) male and female students (194 males and 184 females). The total sample individuals living in camps and studying in their schools is (191) students, and 187) students of those living in the City of Zarqa and studying in Zarqa schools.

\subsection{Study Instrument}

For the purposes of this study, the researcher utilized the psychological alienation scale, which was prepared by Dr. 
Na'eeseh (2012), of the Faculty of Education, Damascus (Syria) University, who applied it in her study titled: "A Field Study on a Sample of Damascus University Living in the Campus."

The test includes seventy items with seven dimensions:

- $\quad$ Lack of belonging: items 1-10

- $\quad$ Normlessness: items 11-20

- Powerlessness: items 21-30

- $\quad$ Lack of feeling of value: items 31-40

- Loss of aim : items 41-50

- Meaninglessness : items 51-60

- Self-Centrality: items 61-70

\subsubsection{Explanatory Study of the Psychological Alienation Scale}

In order to ensure the clarity of the scale statements and instructions, the researcher carried out an explanatory study. She applied the scale on a small sample $(n=40)$ of male and female students at the Faculty of Education, Damascus University. As a result of this explanatory study, the scale statements remained as they are, as well as the instructions of the instrument, as it turned out to be very clear and understood.

\subsubsection{Correction Method, Scale Validity and Reliability}

Psychological Alienation Scale Method of Correction: Response to the scale statements by choosing one response of the five responses (strongly agree, agree, sometimes, disagree, strongly disagree. The positive responses are given the grades: $1,2,3,4$, and 5, respectively, meanwhile, the negative responses are given the grades: 5, 4, 3, 2, and 1 , respectively. In other words, the highest possible grade the student may acquire on all the scale statements is 350 , and the least is 70 degrees. The average grade of the scale is (210),so as to relatively judge the prevalence of the alienation phenomenon.

\subsubsection{Validity of the Psychological Alienation Scale}

Apparent Validity: For the purpose of assuring the validity of the psychological alienation scale statements, it was presented to a number of the faculty members of the Faculty of Education, Damascus University, to have their opinion about the validity and accuracy of each statement, degree of its suitability to the domain; in addition to provide what they see suitable of additions or amendments. Accordingly, none of the scale statements was disregarded, but some of them were modified in terms of method and wording. As a result, the final total of the statements of this scale was (70) items, which were distributed randomly over its dimensions.

\subsubsection{Reliability of the Psychological Alienation Scale}

Reapplication: The reliability coefficient was calculated by applying the scale, and reapplying it on the same sample two weeks later. The results showed that the scale enjoys high reliability degree, which was (0.85).

Halftone Division: In this way, the scale items were divided into two equal halves, in which the first half comprised the odd items $(1,3,5 \ldots)$ and the second comprised the even items $(2,4,6 \ldots)$. Every part consisted of (35) items, and Spearman Brown and Gottman correlation coefficient was calculated between the two parts. The results were as follows: Spearman Brown coefficient was (0.846) and Gottman coefficient was (0.852), all of which are of significance at (0.01) significance level.

\section{Procedures}

Research procedures included the following steps:

A- School visits: The researcher visited Mraijeeb Al-Fohood Camp School and Al-Mkhaizen Camp School to apply the questionnaire as follows:

1- Two visits to Mraijeeb Al-Fohood Secondary Boys' School, where the scale (the questionnaires) was distributed to 54 male students. 
2- Two visits to Mraijeeb Al-Fohood Secondary Girls' School, where the scale (the questionnaires) was distributed to 46 female students.

3- Visit to Al-Mkhaizen Secondary Girls' School, where the scale (the questionnaires) was distributed to 43 female students.

4- Visit to Al-Mkhaizen Secondary Boys' School, where the questionnaire was distributed to 48 of the ninth and tenth graders.

B- The second stage which included visit to the refugees residing in the City of Zarqa to distribute the questionnaire, as follows.

5- Visit to Umm Kolthoum Secondary Girls' School, where the questionnaire was distributed to 48 female ninth and tenth graders.

6- Visit to Al-Khawarizmi Boys' School, where the questionnaire was distributed to 52 male ninth and tenth graders.

7- Visit to RayhanaBInt Zaid Girls' School, in Al-Hashkiah Town, where the questionnaire was distributed to 39 female students.

8- Visit to Iskan al-Hashmiah Secondary Boys' School, where the questionnaire was distributed to 40 male students.

C- The grades of every student were posted according to the scale correction key, and calculation of the grade of every student.

\section{Statistical Methods}

- Means (M) and standard deviations (SD).

- T-Test

- $\quad$ One Way ANOVA (Analysis)

\section{Results and Discussion}

Below are the results of this study and their interpretation, arranged in an order according to the study questions.

1) What is the degree of alienation of the Syrian refugee students?

For answering this question, the means (M's) and standard deviations (SD's) of every domain/dimension of the alienation were calculated. Table (1) illustrates this.

\begin{tabular}{|l|c|c|l|}
\hline Domain/Dimension & M & SD & Alienation Degree \\
\hline Frist: Loss of Feeling & 3.32. & 0.56 & Medium \\
\hline Second: Normlessness & 3.20 & 0.61 & Medium \\
\hline Third: Powerlessness & 2.19 & 0.57 & Low \\
\hline Fourth: Lack of Value Feeling & 2.33 & 0.68 & Low \\
\hline Fifth: Loss of aim & 1.95 & 0.68 & Low \\
\hline Sixth: Meaninglessness & 2.11 & 0.59 & Low \\
\hline Seventh: Self-Centrality & 2.80 & 0.34 & Medium \\
\hline
\end{tabular}

Table (1) shows that the alienation feeling degree of the Syrian refugee students was medium to the first, second and seventh dimensions, was medium; meanwhile it was low to the third, fourth fifth and seventh dimensions. This study is in agreement with Al-Aqeel study (2014), which indicated the existence of a medium alienation degree with the refugees.

The fifth domain was the least as compared with the other dimensions. The reason may be that achieving the objectives does not fall within the circle of their interests, in the light of their sufferings as a result of the hardship of their alienation conditions.

2) Are there statistically significant differences at $(\alpha=0.05)$ level in the alienation degree of the Syrian refugee students, ascribed to gender (male, female)?

For answering this question, the means (M's), standard deviations (SD's), and T value of every domain of the alienation were calculated, according to the gender variable (male, female); as clearly illustrated in Table (2). 
Table (2): M's, SD's and T Value of the Degrees of the Sample Members on the Seven Dimension of the Alienation Scale According to the Gender Variable

\begin{tabular}{|c|c|c|c|c|c|c|c|c|}
\hline \multirow[t]{3}{*}{ Dimensions } & \multicolumn{6}{|c|}{ Gender } & \multirow{3}{*}{ T Value } & \multirow{3}{*}{ Significance } \\
\hline & \multicolumn{3}{|c|}{ Males } & \multicolumn{3}{|c|}{ Females } & & \\
\hline & No. & $\mathrm{M}$ & SD & No. & $M$ & $\mathrm{SD}$ & & \\
\hline First & 194 & 2.97 & 0.43 & 184 & 3.69 & 0.43 & -16.208 & ${ }^{*} 0.00$ \\
\hline Second & 194 & 2.77 & 0.38 & 184 & 3.65 & 0.47 & -20.163 & ${ }^{\star} 0.00$ \\
\hline Third & 194 & 2.12 & 0.59 & 184 & 2.26 & 0.55 & -2.476 & ${ }^{\star} 0.01$ \\
\hline Fourth & 194 & 2.23 & 0.71 & 184 & 2.43 & 0.65 & -2.840 & ${ }^{*} 0.00$ \\
\hline Fifth & 194 & 1.96 & 0.71 & 184 & 1.93 & 0.64 & 0.375 & 0.70 \\
\hline Sixth & 194 & 2.03 & 0.48 & 184 & 2.19 & 0.68 & -2.695 & ${ }^{*} 0.00$ \\
\hline Seventh & 194 & 2.67 & 0.35 & 184 & 2.93 & 0.26 & -8.142 & ${ }^{*} 0.00$ \\
\hline
\end{tabular}

Table (2) indicates that there are statistically significant differences at the $(\alpha=0.05)$ level, in the alienation feeling degree with the Syrian refugee students, attributed to the gender variable in the first, second, third, fourth, sixth and seventh dimensions. Meanwhile, there were no statistically significant differences in the alienation feeling degree with the Syrian refugee students, attributed to the gender variable in the fifth dimension.

The results showed that the females are feeling alienation more than the males in all the dimensions, except for the fifth dimension. This result in in agreement with the study conducted by Bushra (2006), which showed statistically significant differences between the males and females on the alienation scale. It is also in line with the study of Mohammad (2000) which showed that the females were more feeling alienation more than the males. It further agreed with the study of Al-Aqeeli (2014) which indicated that the meaninglessness level, one of the alienation levels, was more with the females than that of the males.

3) Are there statistically significant differences at $(\alpha=0.05)$ level in the alienation degree of the Syrian refugee students, ascribed to the years of alienation?

For answering this question, the One Way ANOVA analysis for all the dimensions of alienation, in accordance with the years of alienation variable (one, two, three years); as shown in Table (3).

Table (3): Results of ANOVA Analysis as per the Number of Alienation Years

\begin{tabular}{|c|c|c|c|c|c|c|}
\hline \begin{tabular}{|l|} 
Dimensions \\
\end{tabular} & \multicolumn{2}{|c|}{ Total of the Squares } & \begin{tabular}{|l|} 
Freedom Degree \\
\end{tabular} & Squares Average & \begin{tabular}{|l|} 
F Value \\
\end{tabular} & Significance \\
\hline \multirow[t]{3}{*}{ First Domain } & Inter-Groups & 0.933 & 2 & 0.466 & \multirow{3}{*}{1.490} & \multirow{3}{*}{0.22} \\
\hline & Intra-Groups & 117.372 & 375 & 0.313 & & \\
\hline & Total & 118.305 & 377 & & & \\
\hline \multirow[t]{3}{*}{ Second Domain } & Inter-Groups & 0.488 & 2 & 0.224 & \multirow{3}{*}{0.592} & \multirow{3}{*}{0.55} \\
\hline & Intra-Groups & 141.991 & 375 & $0 / 379$ & & \\
\hline & Total & 142.440 & 377 & & & \\
\hline \multirow[t]{3}{*}{ Third Dimension } & Inter-Groups & 4.073 & 2 & 2.037 & \multirow{3}{*}{6.342} & \multirow{3}{*}{${ }^{\star} 0.00$} \\
\hline & Intra-Groups & 120.415 & 375 & 0.321 & & \\
\hline & Total & 124.488 & 377 & & & \\
\hline \multirow[t]{3}{*}{ Fourth Dimension } & Inter-Groups & 2.868 & 2 & 1.434 & \multirow{3}{*}{3.090} & \multirow{3}{*}{ *0.04 } \\
\hline & Intra-Groups & 174.008 & 375 & 0.464 & & \\
\hline & Total & 176.876 & 377 & & & \\
\hline \multirow[t]{3}{*}{ Fifth Dimension } & Inter-Groups & 4.620 & 2 & 2.310 & \multirow{3}{*}{5.165} & \multirow{3}{*}{$* 0.00$} \\
\hline & Intra-Groups & 167.719 & 375 & & & \\
\hline & Total & 172.339 & 377 & & & \\
\hline \multirow[t]{3}{*}{ Sixth Dimension } & Inter-Groups & 0.858 & 2 & 0.429 & \multirow{3}{*}{1.230} & \multirow{3}{*}{029} \\
\hline & Intra-Groups & 130.915 & 375 & & & \\
\hline & Total & 131.773 & 377 & & & \\
\hline \multirow[t]{3}{*}{ Seventh Dimension } & Inter-Groups & 0.190 & 2 & 0.095 & \multirow{3}{*}{0.844} & \multirow{3}{*}{043} \\
\hline & Intra-Groups & 42.301 & 375 & 0.113 & & \\
\hline & Total & 42.491 & 377 & & & \\
\hline
\end{tabular}

The above table shows statistically significant differences atthe $(\alpha=0.05)$ level, in the alienation feeling degree with the Syrian refugee students, attributed to the number of alienation years in the third dimension (inability), the fourth (lack of 
value feeling), and the fifth dimensions (loss of the objectives). On the other hand, there were no statistically significant differences in the alienation feeling degree with the Syrian refugee students, attributed to the number of alienation years in the first, second, sixth seventh dimensions. In order to identify these differences, Scheffe test for the posteriori comparisonswas applied, as illustrated in Tables (4,5 and 6). This indicates that the more the alienation years are, the more the feeling of inability, loss of target, and lack of value feeling increase the alienation feeling.

Table No. (4): Results of Scheffe test for Posteriori Comparisons, According to the Years of Alienation Variable Concerning the Third Dimension

\begin{tabular}{|l|c|c|c|}
\hline Years of Alienation & One Year & Two Years & Three Years \\
\hline One year & & ${ }^{*}-0.27$ & \\
\hline Two Years & & & \\
\hline Three Years & & ${ }^{*}-0.27$ & \\
\hline
\end{tabular}

Table No. (4) shows statistically significant differences in the alienation feeling according to the alienation years variable (one year, three years), on the third dimension.

Table No. (5): Results of Scheffe test for Posteriori Comparisons, According to the Years of Alienation Variable Concerning the Fourth Dimension

\begin{tabular}{|l|c|c|c|}
\hline Years of Alienation & One Year & Two Years & Three Years \\
\hline One year & & & \\
\hline Two Years & & ${ }^{*}-0.23$ & \\
\hline Three Years & & ${ }^{*}-0.23$ & \\
\hline
\end{tabular}

Table No. (5) shows statistically significant differences in the alienation feeling according to the alienation years variable (two years, three years), on the fourth dimension

Table No. (6): Results of Scheffe test for Posteriori Comparisons, According to the Years of Alienation Variable Concerning the Fifth Dimension

\begin{tabular}{|l|c|c|c|}
\hline Years of Alienation & One Year & Two Years & Three Years \\
\hline One year & & & \\
\hline Two Years & & ${ }^{*}-0.23$ & \\
\hline Three Years & & ${ }^{*}-0.23$ & \\
\hline
\end{tabular}

Table No. (6) shows statistically significant differences in the alienation feeling according to the alienation years variable (two years, three years), on the fifth dimension.

Building on the above results, we conclude that the more the alienation years are, the more the psychological alienation is, which was more indicative on the third, fourth, and fifth dimensions.

4) Are there statistically significant differences at $(\alpha=0.05)$ level in the alienation degree of the Syrian refugee students, ascribed to academic achievement?

For answering this question, the One Way ANOVA analysis for all the dimensions of alienation, in accordance with the academic achievement variable (excellent, very good, good, acceptable); as shown in Table (7).

Table (7): Results of ANOVA Analysis as per the Academic Achievement

\begin{tabular}{|c|c|c|c|c|c|c|}
\hline \multirow{2}{*}{\begin{tabular}{|l|} 
Dimensions \\
First Domain \\
\end{tabular}} & \multicolumn{2}{|c|}{ Total of the Squares } & \multirow{2}{*}{\begin{tabular}{|c|} 
Freedom Degree \\
3 \\
\end{tabular}} & \multirow{2}{*}{$\begin{array}{c}\text { Squares Average } \\
1.144 \\
\end{array}$} & F Value & Significance \\
\hline & Inter-Groups & 3.433 & & & \multirow{3}{*}{3.726} & \multirow{3}{*}{0.01} \\
\hline & Intra-Groups & 114.872 & 374 & 0.307 & & \\
\hline & Total & 118.305 & 377 & & & \\
\hline \multirow[t]{3}{*}{ Second Domain } & Inter-Groups & 3.471 & 3 & 1.157 & \multirow{3}{*}{3.114} & \multirow{3}{*}{0.02} \\
\hline & Intra-Groups & 138.968 & 374 & 0.372 & & \\
\hline & Total & 142.440 & 377 & & & \\
\hline
\end{tabular}




\begin{tabular}{|c|c|c|c|c|c|c|}
\hline \multirow[t]{3}{*}{ Third Dimension } & Inter-Groups & 6.698 & 3 & 2.320 & \multirow{3}{*}{7.384} & \multirow{3}{*}{0.00} \\
\hline & Intra-Groups & 117.528 & 374 & 03.14 & & \\
\hline & Total & 124.488 & 377 & & & \\
\hline \multirow[t]{3}{*}{ Fourth Dimension } & Inter-Groups & 19.584 & 3 & 6.528 & \multirow{3}{*}{15.522} & \multirow{3}{*}{0.00} \\
\hline & Intra-Groups & 157.292 & 374 & 0.421 & & \\
\hline & Total & 176.867 & 377 & & & \\
\hline \multirow[t]{3}{*}{ Fifth Dimension } & Inter-Groups & 15.726 & 3 & 5.242 & \multirow{3}{*}{12.518} & \multirow{3}{*}{0.00} \\
\hline & Intra-Groups & 156.613 & 374 & 0419 & & \\
\hline & Total & 172.339 & 377 & & & \\
\hline \multirow[t]{3}{*}{ Sixth Dimension } & Inter-Groups & 13.300 & 3 & 4.433 & \multirow{3}{*}{13.995} & \multirow{3}{*}{0.00} \\
\hline & Intra-Groups & 118.473 & 374 & 0.317 & & \\
\hline & Total & 131.773 & 377 & & & \\
\hline \multirow[t]{3}{*}{ Seventh Dimension } & Inter-Groups & 2.735 & 3 & 0.912 & \multirow{3}{*}{8.577} & \multirow{3}{*}{0.00} \\
\hline & Intra-Groups & 39.756 & 374 & 0.106 & & \\
\hline & Total & 42.491 & 377 & & & \\
\hline
\end{tabular}

The above table shows statistically significant differences atthe $(\alpha=0.05)$ level, in the alienation feeling degree with the Syrian refugee students, attributed to the academic achievement in the first dimension, second, third, fourth, fifth, sixth and seventh dimensions. This result shows the effect of the alienation feeling reflection on the students' achievement, which most often indicates that the underachievement is inversely associated with the alienation feeling. In other words, the more the alienation feeling, the more the underachievement is. (8-14).

In order to identify the significance of these differences, the researcher employed Scheffe test as shown in tables

Table No. (8): Results of Scheffe Test of the Posteriori Comparisons According to the Academic Achievement of the First Dimension

\begin{tabular}{|l|c|c|c|c|}
\hline Academic Achievement & Excellent & Very Good & Good & Acceptable \\
\hline Excellent & & & & \\
\hline Very Good & & & & ${ }^{*} 0.30$ \\
\hline Good & & & & \\
\hline Acceptable & & ${ }^{*}-0.30$ & & \\
\hline
\end{tabular}

Table (8) indicates statistically significant differences in the alienation feeling with the students of academic underachievement level (acceptable), on the first dimension.

Table No. (9): Results of Scheffe Test of the Posteriori Comparisons According to the Academic Achievement of the Second Dimension

\begin{tabular}{|l|l|l|l|l|}
\hline Academic Achievement & Excellent & Very Good & Good & Acceptable \\
\hline Excellent & & & & \\
\hline Very Good & & & & ${ }^{*} 0.31$ \\
\hline Good & & & & \\
\hline Acceptable & & ${ }^{*}-0.31$ & & \\
\hline
\end{tabular}

Table (9) indicates statistically significant differences in the alienation feeling with the students of academic underachievement level (acceptable) on the second dimension.

Table No. (10): Results of Scheffe Test of the Posteriori Comparisons According to the Academic Achievement of the Third Dimension

\begin{tabular}{|l|c|l|l|l|}
\hline Academic Achievement & Excellent & Very Good & Good & Acceptable \\
\hline Excellent & & & & \\
\hline Very Good & & & ${ }^{*}-0.39$ & \\
\hline Good & & ${ }^{*}-0.39$ & & \\
\hline Acceptable & & & & \\
\hline \multicolumn{5}{|c|}{144}
\end{tabular}


Table (10) indicates statistically significant differences in the alienation feeling with the students with good academic achievement level on the third dimension.

Table No. (11): Results of Scheffe Test of the Posteriori Comparisons According to the Academic Achievement of the Fourth Dimension

\begin{tabular}{|l|c|c|c|c|}
\hline Academic Achievement & Excellent & Very Good & Good & Acceptable \\
\hline Excellent & & ${ }^{*}-0.48$ & & ${ }^{*} 0.58$ \\
\hline Very Good & ${ }^{*} 0.48$ & & ${ }^{*}-0.56$ & \\
\hline Good & & ${ }^{*} 0.56$ & & \\
\hline Acceptable & & ${ }^{*}-0.58$ & & \\
\hline
\end{tabular}

Table (11) indicates statistically significant differences in the alienation feeling with the students with very good, good and acceptable academic achievement levelson the fourth dimension.

Table No. (12): Results of Scheffe Test of the Posteriori Comparisons According to the Academic Achievement of the Fifth Dimension

\begin{tabular}{|l|c|c|c|c|}
\hline Academic Achievement & Excellent & Very Good & Good & Acceptable \\
\hline Excellent & & ${ }^{*}-0.43$ & & \\
\hline Very Good & ${ }^{*} 0.43$ & & ${ }^{*} 0.59$ & ${ }^{*} 0.48$ \\
\hline Good & & ${ }^{*}-0.59$ & & \\
\hline Acceptable & & ${ }^{*}-0.48$ & & \\
\hline
\end{tabular}

Table (12) indicates statistically significant differences in the alienation feeling with the students with very good, good and acceptable academic achievement levelson the fifth dimension.

Table No. (13): Results of Scheffe Test of the Posteriori Comparisons According to the Academic Achievement of the Sixth Dimension

\begin{tabular}{|l|c|c|c|c|}
\hline Academic Achievement & Excellent & Very Good & Good & Acceptable \\
\hline Excellent & & ${ }^{\star}-0.32$ & & \\
\hline Very Good & ${ }^{\star} 0.32$ & & ${ }^{*} 0.51$ & ${ }^{\star} 0.52$ \\
\hline Good & & ${ }^{*}-0.51$ & & \\
\hline Acceptable & & ${ }^{*}-0.52$ & & \\
\hline
\end{tabular}

Table (13) indicates statistically significant differences in the alienation feeling with the students with very good, good and acceptable academic achievement levelson the sixth dimension.

Table No. (14): Results of Scheffe Test of the Posteriori Comparisons According to the Academic Achievement of the Seventh Dimension.

\begin{tabular}{|l|c|c|c|c|}
\hline Academic Achievement & Excellent & Very Good & Good & Acceptable \\
\hline Excellent & & & & \\
\hline Very Good & & & ${ }^{*} 0.22$ & ${ }^{*} 0.25$ \\
\hline Good & & ${ }^{*}-0.22$ & & \\
\hline Acceptable & & ${ }^{*}-0.25$ & & \\
\hline
\end{tabular}

Table (14) indicates statistically significant differences in the alienation feeling with the students with good and acceptable academic achievement levelson the seventh dimension.

The above data indicated that there are statistically significant differences of the academic achievement variable for the levels (very good, good and acceptable) on the seven dimensions of the scale. Which assures that achievement is directly associated with the alienation feeling. The more the alienation feeling, the lower the achievement is, because the alienation feeling psychologically reflects on the individuals' performance and ability to challenge and accomplish; as well 
as the emergence of problems in their lives, as the previous studies showed. For example, the study of Bushra (2006) showed a correlational association between the alienation feeling degree and the problems the students face.

5) Are there statistically significant differences at $(\alpha=0.05)$ level in the alienation degree with the Syrian refugee students, ascribed to the place of domicile?

For answering this question, the means (M's), standard deviations (SD's), and T value of every domain of the alienation were calculated, according to the place of residence variable (camp, city); as clearly illustrated in Table (15).

Table (15): M's, D's, and T Value of the Sample Members on the Seven Dimensions of Alienation According to the Place of Residence Variable.

\begin{tabular}{|c|c|c|c|c|c|c|c|c|}
\hline \multirow[t]{3}{*}{ Dimensions } & \multicolumn{6}{|c|}{ Place of Residence } & \multirow{3}{*}{ T Value } & \multirow{3}{*}{ Significance } \\
\hline & \multicolumn{3}{|c|}{ Camp } & \multicolumn{3}{|c|}{ City } & & \\
\hline & No. & $\mathrm{M}$ & SD & No. & $\mathrm{M}$ & SD & & \\
\hline First & 191 & 3.01 & 0.47 & 187 & 3.63 & 0.47 & -12.671 & ${ }^{\star} 0.00$ \\
\hline Second & 191 & 2.98 & 0.54 & 187 & 3.42 & 0.61 & -7.305 & ${ }^{\star} 0.00$ \\
\hline Third & 191 & 2.16 & 0.67 & 187 & 2.21 & 0.46 & 0.872 & 0.38 \\
\hline Fourth & 191 & 1.95 & 0.74 & 187 & 2.70 & 0.32 & -12.912 & ${ }^{\star} 0.00$ \\
\hline Fifth & 191 & 1.96 & 0.74 & 187 & 1.92 & 0.60 & 0.457 & 0.64 \\
\hline Sixth & 191 & 2.00 & 0.67 & 187 & 2.22 & 048 & $-3 / 592$ & ${ }^{\star} 0.00$ \\
\hline Seventh & 191 & 2.59 & 0.29 & 187 & 3.02 & 0.22 & -16.325 & ${ }^{\star} 0.00$ \\
\hline
\end{tabular}

Table (15) indicates that there are statistically significant differences at the $(\alpha=0.05)$ level, in the alienation feeling degree with the Syrian refugee students, attributed to the place of residence variable in the first, second, fourth, sixth and seventh dimensions. Meanwhile, there were no statistically significant differences in the alienation feeling degree with the Syrian refugee students, attributed to the gender variable in the third dimension (inability), and fifth dimension (loss of objective). The results showed according to the M's of the residence place (city, camp) that the students residing in the cities were more feeling of alienation. This may be attributed to the fact that the residents in the city feel more alienation, because they mix with citizens who enjoy stability and security without alienation feelings. So, the Syrian refugee students feel that they are a burden and strangers for this reality. As for those residing in the camps, they suffer the same problem and factuality, and they may be more adaptive to their reality.

\section{References}

Arabic References:

AlAqeeeli, Adel (2004) Alienation and Its Relation to Psychological Security, MA Thesis, Social Sciences Department, Faculty of Post Graduates, Nayef Arab University of the Security Sciences. Riyadh, Saudi Arabia.

AlMahmadawi, Hasan. (2007) Relation between Alienation and Psychological Adjustment of the Iraqi Community in Sweden, A Doctoral Dissertation, Faculty of Arts and Education, Arab Open Academy in Denmark, Copenhagen. Denmark.

AlNaeemi,Lateefah,Majed (2005) Certain Types of Alienation and Its Relation with the Needs of the Faculty Members, , Al-Mustansiriah University.

Ali, Bushra (2006) Psychological Alienation with the Syrian Students Studying Outside the Syrian Universities, and Its Relation with the Problems they Face, Unpublished Doctoral Dissertation, Damascus University, Syria.

Ali, Bushra. (2008), Alienation Features with the Syrian Students Studying in Some Egyptian Universities, Damascus University Journal, Vol. (24) (1),, Damascus.

Damanhouri, Rashad Saleh and Medhat Abdulhamid(1990) Alienation Feeling about the Self and Others, Factorial, Civilization, Comparative Study, Psychology Journal, No. 13.

Iskander, Nabil Ramzi (1988) Psychological Alienation and its Relation with the Contemporary Man Crisis. Dar Al-Ma'rifa Al-Jamiyah, Alexandria.

Mohammad, Yousef Abdelfattah (2000) Alienation Feelings and Their Relation to Some Personality Traits. Unpublished MA Thesis, Psychology Department, Faculty of Education, Damascus University, Damascus.

Na'eesa, Raghda'a (2012) "Psychological Alienation and its Relation to the Psychological Security. A Field Study on a Sample of Damascus University Students Residing in the University Campus. Damascus University Journal, Vol. (28) No.3. Damascus.

Zahran, Sanaa Hamed. (2004) Psychological Health Counseling for Correcting the Alienation Feelings . Cairo,Aalam Al-Kotob.

English References

Alfred, P. Rovail\& Mervyn J. Wighting (2005) Feeling of alienation and community among higher education students in virtual classroom." Internet and higher education 8. 
Anastasi, A . (1976) Psychological Testing , Mac - Miller, New York.

Daugherty, T.K. \&Lintor, J.M. (2003). Assessment of Social Alienation: Psychometric Properties of the Sacs-R, Social .

Hegel, G.W. (1977) "Hegel's Phenomenology of Spirit .translated by Miller, A.V), Oxford University Press.

Kobasa, S.C. ( 1979) "Stressful live events of personality and health an inquiry into hardiness. Journal of Personality and Social Psychology, 3.

Leak, G.K. \& Williams, D.E.(1989) Relationship between social Interest, Alienation and Psychological Hardiness. Individual Psychology, 453.

MahoneyJohn and Quick,Ben (2001) Personality correlates of alienation in a university sample, Psychological reports vol. 87.

Mau, R.Y.(1992) The validity and devolution of a concept, Student Alienation Adolescence,24, 107.

Mahoney, John \& Quick, Ben (2001) Personality Correlates ofAlienation in a university sample. Psychological reports, VOL. (87), (3,pt2), P.P: $1094-1100$.

Marc Schabracq\& Cary Cooper (2003) To be me or not to be me: about alienation. Counselling Psychology Quarterly,16,2.

Marc, Schabracq \& Cary Cooper (2003) To be me or not to be , Paik, Chie \& Michael.

Paik, Chie \& Michael, William B. (2002),Further Psychometric Evaluation of the Japanese Version of An Academic Self Concept Scale .Journal of Psychology, May 2002, Vol. 136, Issue 3.

Semmer, N. K. (2002) Individual differences, Work Stress and Health ; Handbook of work and health psychology,Chichester. J.Wiley and sons.

Sugiura, Takeshi (2000). Developmental change in the relation between two affiliation motives and interpersonal alienation. Alienation motifs in Meliven.Seeman 1983.

William.B. (2002) Further Psychometric Evaluation of the Japanese Version of an Academic Self Concept Scale. Journal of Psychology, May 2002 , Vol. 136 , Issue.

Yahya, H. Affinnih (1997). A Critical Reexamination of alienation; The social science journal, 34,3. 
